\section{Streptococcus pyogenes aortic aneurysm infection: forgotten but not gone}

\author{
Bradley J. Gardiner,' Joy Wong, ${ }^{2}$ \\ Ming Yii, ${ }^{2}$ Timothy Buckenham, ${ }^{3}$ \\ Tony M. Korman ${ }^{1,4}$
}

Departments of 'Infectious Diseases, ${ }^{2}$ Vascular Surgery and ${ }^{3}$ Radiology Monash Health, Clayton, Victoria; ${ }^{4}$ Department of Medicine, Monash University, Clayton, Victoria, Australia

\begin{abstract}
Historically, Streptococcus pyogenes was a common cause of endocarditis and infected aortic aneurysm. Today, endovascular infections due to this organism have become exceedingly rare. We report the first case of aortic aneurysm infection due to $S$. pyogenes treated with initial endoluminal repair, review previous reports and discuss current treatment options.
\end{abstract}

\section{Case Report}

A 60 year old man had a past history of smoking, non-alcoholic steatohepatitis and a left ileofemoral bypass with a Polyethylene Terephthalate (Dacron) graft 7 years earlier. His only regular medication was esomeprazole. He became unwell during a trip to the United Kingdom, with sore throat, fevers and sweats. On return to Australia, fever and night sweats persisted, and he had $8 \mathrm{~kg}$ weight loss. Four weeks later he presented with back pain, an abdominal computed tomography (CT) scan revealed a para-aortic mass (Figure 1), and he was referred to our emergency department for further management. On examination he was afebrile, heart rate 60 beats/min, normotensive with a pulsatile non-tender abdominal mass. White cell count (WCC) was $13.9 \times 10^{9} / \mathrm{L}$ and C-reactive protein (CRP) $207 \mathrm{mg} / \mathrm{L}$. As he was clinically stable, empiric antibiotic therapy was withheld. Multiple blood cultures were obtained and a CT-guided biopsy of the periaortic mass was performed. Following the biopsy, he developed fever $\left(40^{\circ} \mathrm{C}\right)$ and rigors, and intravenous ceftriaxone $2 \mathrm{~g}$ every 24 hours, vancomycin $1.5 \mathrm{~g}$ every 12 hours and metronidazole $500 \mathrm{mg}$ every 12 hours were commenced. Blood cultures and biopsy specimens revealed pure growth of Streptococcus pyogenes, later confirmed as emm type 44 . Antimicrobial therapy was modified to iv ben- zylpenicillin $2.4 \mathrm{~g} \mathrm{q} 4 \mathrm{~h}$ alone. Transoesophageal echocardiography revealed no evidence of endocarditis. He was progressing well until day 7 when he developed worsening abdominal pain. Repeat abdominal CT scan revealed a contained rupture of the aneurysm. He underwent urgent endovascular aortic aneurysm stent graft repair. Fever resolved in 72 hours, and inflammatory markers reduced (Day 4: WCC $15.3 \times 10^{9} / \mathrm{L}$ and CRP $430 \mathrm{mg} / \mathrm{L}$; Day 13 WCC $6.8 \times 10^{9} / \mathrm{L}$ and CRP $\left.66 \mathrm{mg} / \mathrm{L}\right)$. He was discharged on day 15 and continuous infusion intravenous benzylpenicillin was continued via an outpatient antimicrobial therapy program, with a plan for 6 weeks therapy followed by lifelong oral amoxicillin.

However he had ongoing weight loss, anorexia, his inflammatory markers failed to normalise. On day 53, he underwent graft explantation and axillo-bifemoral bypass. This was complicated by graft occlusion requiring therapeutic anticoagulation, and subsequent intra-abdominal haemorrhage. This ultimately resulted in irreversible ischemia of his left lower limb requiring below knee amputation. Culture of the explanted graft revealed Klebsiella oxytoca, Enterococcus faecalis, and methicillin-sensitive Staphylococcus capitus and Staphylococcus epidermidis, but Streptococcus pyogenes was not reisolated. Repeat CT imaging revealed no source of infection, and there was no evidence of intestinal pathology at the time of laparotomy. He was treated with intravenous piperacillin/ tazobactam 4.5 g every 8 hours for a further 6 weeks, followed by oral amoxicillin/clavulanate, with a plan for lifelong antimicrobial therapy. On review 4 months after the initial presentation, he was recovering uneventfully and inflammatory markers had normalised.

\section{Discussion}

Streptococcus pyogenes is an organism associated with a diverse range of clinical presentations. It has multiple virulence factors facilitating pus liquefaction and spread through tissue planes, which give it the ability to cause highly invasive infections such as necrotizing fasciitis. $S$. pyogenes is not typically thought to be associated with endovascular infections. Interestingly, infectious diseases textbooks state that in the pre-antibiotic era $S$. pyogenes was often associated with endovascular infections, ${ }^{1}$ along with Streptococcus pneumoniae and Haemophilus influenzae. A review of the limited available primary data from this time however suggests that the predominant organisms were viridans streptococci, and $S$. pyogenes was in fact unusual. In a widely-referenced 1923 review of 217 cases of mycotic aneurysms (mostly associated with endocardi-
Correspondence: Bradley J. Gardiner, Monash Infectious Diseases, Monash Health, 246 Clayton Road, Clayton, VIC 3168, Australia.

Tel. +61.395.944.564 - Fax: +61.395.944.533

E-mail: bradgardiner@gmail.com

Key words: Streptococcus pyogenes, aortic aneurysm infection, mycotic aneurysm.

Contributions: BJ, patient care, primary author; JW, patient care, secondary author; MY, treating surgeon, contributing author, approval of manuscript; TB, interventionalist, contributing author, approval of manuscript; TK, patient care, supervising author.

Conflict of interests: the authors declare no potential conflict of interests.

Received for publication: 4 July 2013.

Revision received: 7 August 2013.

Accepted for publication: 7 August 2013.

This work is licensed under a Creative Commons Attribution NonCommercial 3.0 License (CC BYNC 3.0).

(C) Copyright B.J. Gardiner et al., 2013

Licensee PAGEPress, Italy

Infectious Disease Reports 2013; 5:e11

doi:10.4081/idr.2013.e11

tis), Stengel and Wolfert comment the organisms most frequently recovered from blood cultures from the heart valves or from aneurysms have been streptococci, mostly non-haemolytic types. ${ }^{2}$ Another early review by Revell et al. ${ }^{3}$ examines 24 cases of primary mycotic aneurysm from 1905-1939, of which 13 had a causative organism identified, 6 of which were streptococci (no further details available). The term mycotic, initially used to refer to all microorganisms, has for some time now been reserved for fungal infections. Mycotic aneurysm has persisted for longer, but has now been surpassed by the more accurate infected aortic aneurysm.

The introduction of penicillin had a dramatic effect on the overall incidence and epidemiology of infected aortic aneurysms. There has been a shift away from an association with endocarditis, and although streptococci remain important causative organisms, Staphylococcus aureus and Salmonella species predominate. ${ }^{4}$

We identified eight cases of infected aortic aneurysm due to $S$. pyogenes described in the literature (Table 1). ${ }^{5-12}$ One died soon after presentation following aneurysm rupture, but seven patients underwent early open surgical repair. Our case represents the first reported case of initial endoluminal repair. Five of seven patients survived the initial post-operative period and were treated with prolonged periods of intravenous and oral penicillin $(6$ 
weeks to 1 year), although details of antibiotic treatment were not available for all cases. Surviving patients were reported to be well at follow-up, ranging from 6 weeks to 87 months.

No randomized controlled trials are available to guide management of infected aortic aneurysm. Given the wide spectrum of potential organisms, obtaining a microbiological diagnosis is of critical importance. There is a high mortality rate associated with conservative therapy. Intervention should be timed before rupture if possible, as emergency procedures have a higher risk of complications. Interestingly, gram-negative aneurysms are more likely to rupture early $(80 \%$ within 2 weeks versus $10 \%$ for gram positives). ${ }^{1}$

Surgical options include open debridement with either extra-anatomic bypass or local reconstruction, endovascular repair, a hybrid approach, or a staged procedure. Anatomical location is a key factor, with an endovascular approach ideal for difficult-to-access descending thoracic aneurysms, but open repair traditionally preferred for juxta- and infra-renal aneurysms. ${ }^{13}$

Endoluminal repair is rapidly becoming an increasingly popular treatment option for the repair of non-infected aortic aneurysms. Advantages include a smaller incision, shorter operation time with less blood loss and transfusion requirements and reduced intensive care stay. It does not require cardiopulmonary bypass, aortic cross-clamping, or single lung ventilation, and overall has reduced early morbidity and mortality, with equivalent long-term outcomes. ${ }^{14}$ It is a tempting option for infected aneurysms as well, particularly in high-risk patients. It does not however allow adequate surgical debridement of the infected area, leading to concern regarding the long-term consequences of direct insertion of prosthetic material into an infected field, and slower uptake in this area. ${ }^{15}$

Setacci et al. ${ }^{16}$ review 6 retrospective studies comparing endovascular with open approaches

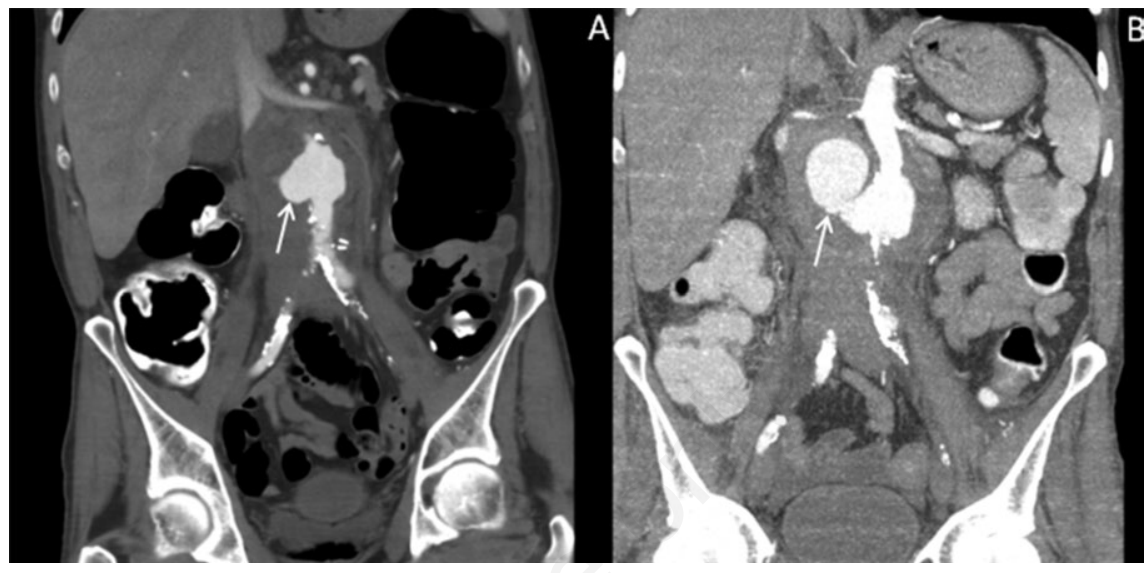

Figure 1. Contrast-enhanced coronal section of abdominal CT scan showing the infrarenal sacular mycotic aneurysm (see arrow) on presentation (A) and following contained rupture $(B)$.

Table 1. Reported cases of Streptococcus pyogenes aortic aneurysm infection.

\begin{tabular}{|c|c|c|c|c|c|}
\hline Case (ref) & $\begin{array}{l}\text { Age } \\
\text { /Sex }\end{array}$ & Site & Surgical treatment & $\begin{array}{l}\text { Medical treatment } \\
\text { (empiric; directed) }\end{array}$ & Outcome \\
\hline $1(5)$ & $65 / \mathrm{M}$ & Infrarenal abdominal aorta & $\begin{array}{l}\text { Resection with right axillary } \\
\text { femoro-femoral bypass graft (day 1) }\end{array}$ & $\begin{array}{l}\text { Ampicillin-sulbactam \& aztreonam; } \\
\text { nafcillin \& penicillin G }\end{array}$ & $\begin{array}{l}\text { Died } 40 \text { hours after } \\
\text { admission }\end{array}$ \\
\hline $2(6)$ & $58 / \mathrm{F}$ & Infrarenal abdominal aorta & Aorto-bifemoral graft & Not discussed "antibiotics" & $\begin{array}{l}\text { Lumbar plexopathy and } \\
\text { flaccid paralysis; walking } \\
\text { with sticks at } 18 \text { months }\end{array}$ \\
\hline $3(7)$ & $36 / \mathrm{M}$ & $\begin{array}{l}\text { Aberrant origin right } \\
\text { subclavian artery }\end{array}$ & $\begin{array}{l}\text { Ligation of aberrant artery; } \\
\text { aortic arch repair with } \\
\text { Hemashield graft (day 2) }\end{array}$ & Not discussed "parenteral antibiotics" & $\begin{array}{l}\text { Death day } 8 \text { - brain } \\
\text { death due to diffuse brain ischemia, } \\
\text { obstructive hydrocephalus due to } \\
\text { cerebellar infarct, \& transverse sinus } \\
\text { thrombosis }\end{array}$ \\
\hline $4(8)$ & $1.5 / \mathrm{F}$ & Ascending aorta & $\begin{array}{l}\text { Aneurysmectomy }+ \\
\text { valveless aortic homograft } \\
\text { on day } 8\end{array}$ & $\begin{array}{l}\text { Cefuroxime \& gentamicin; } \\
\text { high dose penicillin } G \\
\text { ( } 6 \text { weeks), oral penicillin ( } 3 \text { months) }\end{array}$ & Well and active at 12 months \\
\hline $5(9)$ & $81 / \mathrm{M}$ & $\begin{array}{l}\text { Abdominal aorta, } \\
\text { vertebral osteomyelitis, } \\
\text { bilateral psoas abscess }\end{array}$ & None & Not discussed & Died (aneurysm rupture) \\
\hline $6(10)$ & $72 / \mathrm{M}$ & Thoraco-abdominal aorta & $\begin{array}{l}\text { Open resection \& prosthetic } \\
\text { graft implanatation } \\
\text { (rifampicin-impregnated) }\end{array}$ & $\begin{array}{l}\text { Vancomycin \& imipenem; } \\
\text { penicillin G ( } 4 \text { million units q4h } 12 \text { days), } \\
\text { benzathine penicillin lyr }\end{array}$ & Well at 6 months on penicillin \\
\hline $7(11)$ & $63 / F$ & Thoraco-abdominal aorta & $\begin{array}{l}\text { Open Type IV repair } \\
\text { (3 weeks after diagnosis) }\end{array}$ & Not discussed & Alive at 87 months \\
\hline $8(12)$ & $2 / \mathrm{M}$ & Descending thoracic aorta & $\begin{array}{l}\text { Open Dacron repair (day } 3 \text { ) } \\
\text { and re-operation due to recurrence } \\
\text { proximal to original graft }\end{array}$ & $\begin{array}{l}\text { Ceftriaxone, ampicillin-sulbactam; } \\
\text { clindamycin \& ampicillin ( } 6 \text { weeks) }\end{array}$ & Well at 6 weeks \\
\hline $\begin{array}{l}9 \\
\text { (current repor }\end{array}$ & 60/M & Infrarenal abdominal aorta & $\begin{array}{l}\text { Initial endoluminal repair, } \\
\text { complicated by secondary graft } \\
\text { infection requiring graft excision } \\
\text { \& axillary-bifemoral bypass }\end{array}$ & $\begin{array}{l}\text { Vancomycin, ceftriaxone \& } \\
\text { metronidazole; benzylpenicillin ( } 5 \text { weeks), } \\
\text { piperacillin-tazobactam ( } 6 \text { weeks), } \\
\text { amoxicillin-clavulanate (lifelong) }\end{array}$ & $\begin{array}{l}\text { Well at } 4 \text { months, on amoxicillin- } \\
\text { clavulanate }\end{array}$ \\
\hline
\end{tabular}


for management of infected aortic aneurysm. In general, an endovascular approach seems to be associated with a lower 30 -day mortality, but higher rate of late deaths and complications. It seems to be a reasonable approach either as a bridge to surgery or in patients who are not candidates for surgery due to age or comorbidities, but can be associated with secondary infection and graft failure. Patients who undergo primary surgery seem to have a higher early mortality rate but possibly a better chance of definitive cure with long-term survival.

In our case, after an initial phase of antibiotic therapy, an urgent endovascular repair was performed due to contained rupture. Although there was initial response to directed antibiotic therapy, deterioration then occurred, requiring endograft excision and axillarybifemoral bypass grafting. Culture of explanted graft revealed polymicrobial secondary infection, requiring a prolonged course of broadspectrum intravenous antibiotics and likely lifelong oral suppressive antibiotics.

\section{Conclusions}

Aortic aneurysm infection is a serious disease with a high mortality rate. We describe a complicated case secondary to $S$. pyogenes, a rare causative pathogen, who initially underwent endoluminal repair. Well-timed intervention in conjunction with effective antibiotics can result in reasonable long-term survival. Directed antimicrobial therapy in combination with complete surgical excision of the infected aorta remains the optimal treatment. Endoluminal repair is an emerging treatment option in particular for those with comorbidities contraindicating surgery, but long term monitoring for secondary infection is recommended.

\section{References}

1. Fowler VG, Scheld WM, Bayer AS. Endocarditis and intravascular infections. Mandell, Douglas, and Bennett's principles and practice of infectious disease, 7th ed. Philadelphia: Churchill Livingstone Elsevier Ltd; 2010.

2. Stengel A, Wolferth CC. Mycotic (Bacterial) aneurysms of intravascular origin. Arch Intern Med 1923;31:527.

3 . Revell S. Primary mycotic aneurysms. Ann Intern Med 1945;22:431-40.

4. Miller DV, Oderich GS, Aubry MC, et al. Surgical pathology of infected aneurysms of the descending thoracic and abdominal aorta: clinicopathologic correlations in 29 cases (1976 to 1999). Hum Pathol 2004;35: 1112-20.

5. Valero G, Cutrona AF, Watanakunakorn C, Talkington DF. Group A Streptococcus septicaemia and an infected, ruptured abdominal aortic aneurysm associated with pharyngitis. Clin Infect Dis 1992;15:525-7.

6. Sing TM, Young N, O'Rourke IC, Tomlinson P. Leaking mycotic abdominal aortic aneurysm. Australas Radiol 1994;38: 310-2.

7. Bisognano JD, Young B, Brown JM et al.
Diverse presentation of aberrant origin of the right subclavian artery: two case reports. Chest 1997;112:1693-7.

8. Barth H, Moosdorf R, Bauer J, et al. Mycotic pseudoaneurysm of the aorta in children. Pediatr Cardiol 2000;21:263-6.

9. Chen SH, Lin WC, Lee $\mathrm{CH}$, Chou WY. Spontaneous infective spondylitis and mycotic aneurysm: incidence, risk factors, outcome and management experience. Eur Spine J 2008;17:439-44.

10. Vallejo N, Picardo NE, Bourke P et al. The changing management of primary mycotic aneurysms. J Vasc Surg 2011;54:334-40.

11. Leiva L, Arroyo A, Porto J, Gesto R. [Mycotic thoraco-abdominal aortic aneurysm secondary to streptococcus pyogenes: are we coming to the past?] Cirugía Española 2009;85:119-20. [Article in Spanish].

12. Hoffman MA, Ramey AK, Jammel J et al. Recurrent mycotic aneurysm in a 2-yearold boy with Group A Streptococcus bacteraemia.Pediatr Infect Dis J 2012;31:1080-2.

13. Gomes MN, Choyke PL, Wallace RB. Infected aortic aneurysms: a changing entity. Ann Surg 1992;215:435-42.

14. Lederle FA, Freischlag JA, Kyriakides TC, et al. Long-term comparison of endovascular and open repair of abdominal aortic aneurysm. NEJM 2012;367:1988-97.

15. Ishida $\mathrm{M}$, Kato $\mathrm{N}$, Hirano $\mathrm{T}$ et al. Limitations of endovascular treatment with stent-grafts for active mycotic thoracic aortic aneurysm. Cardiovasc Intervent Radiol 2002;25:216-8.

16. Setacci C, de Donato G, Setacci F. Endografts for the treatment of aortic 